Research Article

\title{
Links between Temperature Biases and Flow Anomalies in an Ensemble of CNRM-CM5.1 Global Climate Model Historical Simulations
}

\author{
O. Lhotka $\mathbb{D D}^{1,2}$ and A. Farda $\mathbb{D D}^{1}$ \\ ${ }^{1}$ Global Change Research Institute, Czech Academy of Sciences, Brno, Czech Republic \\ ${ }^{2}$ Institute of Atmospheric Physics, Czech Academy of Sciences, Prague, Czech Republic
}

Correspondence should be addressed to O. Lhotka; lhotka.o@czechglobe.cz

Received 14 February 2018; Revised 6 June 2018; Accepted 24 June 2018; Published 19 July 2018

Academic Editor: Anthony R. Lupo

Copyright (C) 2018 O. Lhotka and A. Farda. This is an open access article distributed under the Creative Commons Attribution License, which permits unrestricted use, distribution, and reproduction in any medium, provided the original work is properly cited.

\begin{abstract}
The aim of this study was to evaluate temperature and sea-level pressure (SLP) fields and to analyse a related anomalous flow over midlatitudes simulated by the CNRM-CM5.1 global climate model (GCM). Simulated flow over midlatitudes of the Northern Hemisphere was assessed through flow indices, classified into 11 circulation types. Reference data were taken from the NOAACIRES 20th Century Reanalysis, version 2c. CNRM-CM5.1 exhibited analogous temperature biases to those reported for the mean of the CMIP5 GCMs' ensemble. The most prominent features were an erroneous temperature dipole pattern in the Atlantic Ocean and a warm bias over regions of deep water upwelling (locally exceeding $5^{\circ} \mathrm{C}$ ). The latter feature was associated with negative SLP biases in those regions. Too low pressure was found over midlatitudes of the Northern Hemisphere, and CNRM-CM5.1 simulated too frequent zonal flow in these latitudes. The usage of three ensemble members with different initial conditions did not improve model's outputs because the bias is found to be considerably larger compared to the ensemble members' spread. The study showed that temperature and SLP biases are connected in certain regions, suggesting that improvement of GCMs and development of bias correction methods should be carried out with a complex insight.
\end{abstract}

\section{Introduction}

Projections of a possible future climate and advanced understanding of the climate system largely depend on global climate models (GCMs). Although considerable effort has been made on their improvement over past decades, current generation of GCMs still suffers from errors that lower the credibility of their simulations and bring considerable uncertainties in future climate projections $[1,2]$. Wang et al. [3] reported that CMIP5 GCMs tend to underestimate an intensity of Atlantic meridional overturning circulation (AMOC) [4] and linked this deficiency to cold biases in the Northern Hemisphere and warm biases over the Southern Ocean. Majahan [5] suggested that the decreased AMOC is related to an increased sea ice extent in the Arctic and may have contributed to a too slow decline of the Arctic sea ice since 1979 simulated by
CMIP5 GCMs [6]. In addition, CMIP5 GCMs are not able to reproduce the changes of a sea ice around the Antarctic properly [7].

Possible connections between these large-scale oceanic factors and climate in distant regions have been widely analysed. Many studies assessed possible links between the observed rapid Arctic sea ice loss and modified atmospheric circulation in the Northern midlatitudes [8-10], with consequent impacts on wintertime temperatures $[11,12]$. European temperatures seem to be also related to sea surface temperature (SST) anomalies in the North Atlantic Ocean [13], and even a more distant connection was found by Zhou and $\mathrm{Wu}$ [14] who concluded that heat waves over Eurasia are influenced also by El Niño-Southern Oscillation.

Differences in SST among individual GCMs can explain the majority of the intermodel variability in intensity 
changes of Walker and Hadley circulation cells [15]. This uncertainty propagates to projections of atmospheric circulation and other meteorological variables, such as precipitation and temperature. Moreover, Shepherd [16] concluded that the effect of increased global temperature on atmospheric circulation is not clear, suggesting that climate change in certain regions may possibly be dominated rather by circulation changes than background warming.

Besides these models' drawbacks, climate projections are affected by uncertainties originating from the choice of the emission scenario and from the internal variability of climate [17]. Emission scenarios represent possible ways of human society's development that alter the radiative forcing on climate [18], mainly through a modification of atmospheric chemistry and land-cover changes. In midlatitudes, the uncertainty related to the internal climate variability is primarily associated with atmospheric dynamics, dominated by teleconnection modes [19], such as the North Atlantic Oscillation [20].

The aim of this study was to evaluate global patterns of sea-level pressure (SLP) in relation to a simulated temperature bias. In order to better understand possible dynamic causes of biases in temperature over Northern midlatitudes, we also analysed differences between observed and simulated flow indices over three regions there. Historical simulations of the CNRM-CM5.1 GCM [2] were used, and spatial characteristics of SLP and temperature fields are investigated in three ensemble members (initial condition ensemble), which allows analysing the natural variability simulated by the model. Simulated flow and temperature characteristics are evaluated against the NOAACIRES 20th Century Reanalysis, version 2c, which is available since 1851.

\section{Data and Methods}

2.1. CNRM-CM5.1 Global Climate Model. CNRM-CM5.1 GCM simulations performed by the Czech Hydrometeorological Institute were used. The simulations are available for the extended 1740-2005 period at 6-hour temporal resolution. We used daily means of SLP (averaged 4 daily values) and monthly means of air temperature 2 meters above the surface. The CNRM-CM5.1 GCM was developed by CNRMGAME (Centre National de Recherches MétéorologiquesGroupe d'études de l'Atmosphère Météorologique) and Cerfacs (Centre Européen de Recherche et de Formation Avancée). The GCM contains the ARPEGE-Climat atmosphere component, the NEMO oceanic model, and the GELATO sea-ice component. Three ensemble members of the ARPEGE-Climat atmosphere model with different initial conditions are used. Their horizontal spatial resolution is roughly $150 \mathrm{~km}$ (T127) with global coverage, and the model has 31 vertical levels. Although the model performs considerably better compared to its predecessor, substantial errors in seasonal precipitation and cloud radiative forcing are still present, including the double intertropical convergence zone, the critical underestimation of low clouds on the eastern side of the tropical ocean basins, or the lack of cloudiness over the Northern Hemisphere continents [2]. In addition, Huszar et al. [21] revealed too large Arctic sea ice extent in this GCM. More detailed information about CNRM-CM5.1 is available in the study by Voldoire et al. [2].

2.2. NOAA-CIRES 20th Century Reanalysis. Model simulations were evaluated against the NOAA-CIRES 20th Century Reanalysis V2c. It provides a global analysis of the most likely state of the atmosphere since 1851 at 6-hourly temporal resolution, and it is available in the $192 \times 94$ Gaussian grid [22]. Identical variables (temperature 2 meters above the surface and SLP) were taken in order to evaluate the CNRM-CM5.1 simulations. Seasonal and annual averages of SLP and temperature from CNRM-CM5.1 were interpolated to the aforementioned $192 \times 94$ Gaussian grid using the ordinary kriging method, allowing a direct comparison with the reanalysis.

2.3. Assessment of Model Biases and Circulation Types. We analysed both annual and seasonal global patterns of SLP and temperature bias for the 50-year-long 1956-2005 period. Moreover, globally averaged temperature biases for various time periods (since 1851) were also calculated. Besides the biases, differences among individual ensemble members were also visualised.

SLP biases were associated with anomalous flows in the simulated data, which were quantified through flow indices (flow strength, direction, and vorticity) [23, 24]. The flow indices were calculated identically for both CNRM-CM5.1 and NOAA-CIRES 20th Century Reanalysis V2c using SLP in 16 points, evenly distributed over analysed regions (North America, Europe, and East Asia; Figure 1).

The flow strength (STR) is a vector sum of zonal $(w)$ and meridional $(s)$ flow components (1), and $f$ represents the latitude of the centre $\left(50^{\circ} \mathrm{N}\right)$. SLP values $(\mathrm{hPa})$ in individual points from Figure 1 are indicated by $p 1-p 16$ in the following equations:

$$
\begin{aligned}
\mathrm{STR}= & \sqrt{w^{2}+s^{2}}, \\
w= & 0.5 \times(p 4+p 5)-0.5 \times(p 12+p 13), \\
s= & \frac{1}{\cos (\varphi \times(\pi / 180))} \times(0.25 \times(p 13+2 \times p 9+p 5) \\
& -0.25 \times(p 12+2 \times p 8+p 4)) .
\end{aligned}
$$

The flow direction (DIR) is calculated using an $\operatorname{arctg} 2(w, s)$ function $(2)$. It is similar to the inverse tangent, except that the signs of both arguments $(w, s)$ are used to determine the quadrant of the result:

$$
\mathrm{DIR}=\operatorname{arctg} 2\left(\frac{w}{s}\right) .
$$

Finally, the total vorticity (VORT) is the sum of its zonal (zw) and meridional (zs) components of vorticity (3): 


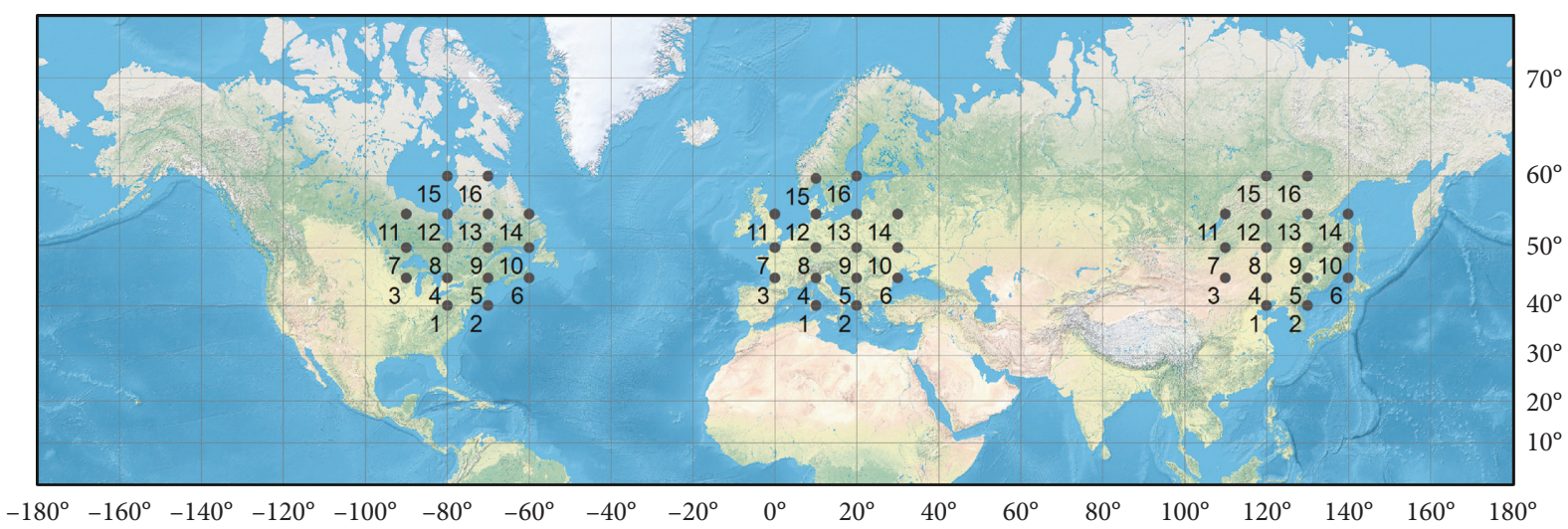

Figure 1: Location of grid points used for the calculation of flow indices over North America, Europe, and East Asia.

$$
\begin{aligned}
\mathrm{VORT}= & \mathrm{zW}+\mathrm{zs}, \\
\mathrm{zW}= & \frac{\sin (\varphi \times(\pi / 180))}{\sin ((\varphi-5) \times(\pi / 180))} \times(0.5 \times(p 1+p 2) \\
& -0.5 \times(p 8+p 9))-\frac{\sin (\varphi \times(\pi / 180))}{\sin ((\varphi+5) \times(\pi / 180))} \\
& \times(0.5 \times(p 8+p 9)-0.5 \times(p 15+p 16)), \\
\mathrm{zs}= & \frac{1}{2 \times(\cos (\varphi \times(\pi / 180)))^{2}} \\
& \times(0.25 \times(p 14+2 \times p 10+p 6)-0.25 \\
& \times(p 13+2 \times p 9+p 5)-0.25 \\
& \times(p 12+2 \times p 5+p 4)+0.25 \\
& \times(p 11+2 \times p 7+p 3)) .
\end{aligned}
$$

Based on these indices, 11 circulation types were calculated. If the STR (flow strength) and the absolute value of VORT (total vorticity) are lower than 3, a pressure pattern is unclassified (U). When the absolute value of VORT is at least four times larger compared to STR, a pressure pattern is classified as cyclonic ( $\mathrm{C}$, if the vorticity is positive) or anticyclonic (A, if the vorticity is negative). When the aforementioned conditions are not met, the pressure pattern is classified based on DIR (the flow direction) into one of the 8 directional types (N, NE, E, SE, S, SW, W, and NW).

\section{Global Patterns of Temperature and Sea-Level Pressure Biases}

The negative bias of annual global temperature in CNRMCM5.1 (approximately $2.8^{\circ} \mathrm{C}$ ) was found during all examined time periods (Table 1), and its magnitude was almost identical among the individual ensemble members.

Spatial patterns of annual temperature in CNRM-CM5.1 for the 1956-2005 period are shown in Figure 2(a).
TABle 1: Annual global temperature $\left({ }^{\circ} \mathrm{C}\right)$ in the NOAA-CIRES 20th Century Reanalysis (V2c), in the CNRM-CM5.1 ensemble mean, and in its individual ensemble members (E1-E3) during four time periods.

\begin{tabular}{lccccc}
\hline Period & $\begin{array}{c}\text { 20th Century } \\
\text { Reanalysis } \\
\text { V2c }\left({ }^{\circ} \mathrm{C}\right)\end{array}$ & $\begin{array}{c}\mathrm{CNRM}-\mathrm{CM} \\
\left({ }^{\circ} \mathrm{C}\right)\end{array}$ & $\begin{array}{c}\mathrm{E} 1 \\
\left({ }^{\circ} \mathrm{C}\right)\end{array}$ & $\begin{array}{c}\mathrm{E} 2 \\
\left({ }^{\circ} \mathrm{C}\right)\end{array}$ & $\begin{array}{c}\text { E3 } \\
\left({ }^{\circ} \mathrm{C}\right)\end{array}$ \\
\hline $1980-2005$ & 14.7 & $12.0(-2.7)$ & 11.9 & 12.0 & 12.0 \\
$1956-2005$ & 14.6 & $11.8(-2.8)$ & 11.8 & 11.8 & 11.8 \\
$1906-2005$ & 14.4 & $11.6(-2.8)$ & 11.6 & 11.6 & 11.6 \\
$1851-2005$ & 14.3 & $11.5(-2.8)$ & 11.5 & 11.5 & 11.5 \\
\hline
\end{tabular}

Temperature biases in the CNRM-CM5.1 ensemble mean are shown in brackets.

Compared to the NOAA-CIRES 20th Century Reanalysis, the CNRM-CM5.1 ensemble mean captured main features reasonably well, but biases were too pronounced in certain regions (Figure 2(b)). Over land, a negative bias prevails, especially over polar regions (both the Arctic and Antarctic) and high-altitude areas. The magnitude of this bias was roughly $5^{\circ} \mathrm{C}$, but it reached $10^{\circ} \mathrm{C}$ in several grid points over the Tibetan Plateau and the Antarctic. Larger terrestrial areas with a positive bias $\left(1-3^{\circ} \mathrm{C}\right)$ were present only over eastern parts of North America. Oceans generally exhibit a cold bias in the Northern Hemisphere and a warm bias in the south. The largest positive bias (around $3^{\circ} \mathrm{C}$, locally exceeding $5^{\circ} \mathrm{C}$ ) was found over the eastern Pacific Ocean, the southeastern Atlantic Ocean, and the Southern Ocean and in the Baffin and Hudson Bays. A bias with a similar magnitude but opposite sign was located over northern Pacific Ocean, northern Atlantic Ocean, and Arctic Ocean. The described overall temperature biases were similar for all ensemble members, especially in the Tropics, where the difference between the "warmest" and "coldest" ensemble members was only 0.1$0.3^{\circ} \mathrm{C}$ (Figure 2(c)). The agreement among the ensemble members was somewhat weaker in the midlatitudes, but differences larger than $1^{\circ} \mathrm{C}$ were still quite rare. The largest variability was found over polar regions, mainly in the Arctic where the difference between the "warmest" and "coldest" ensemble members exceeded $3^{\circ} \mathrm{C}$ in the Barents Sea.

Turning to SLP, CNRM-CM5.1 was able to simulate locations of atmospheric action centres (Figure 3(a)) quite 


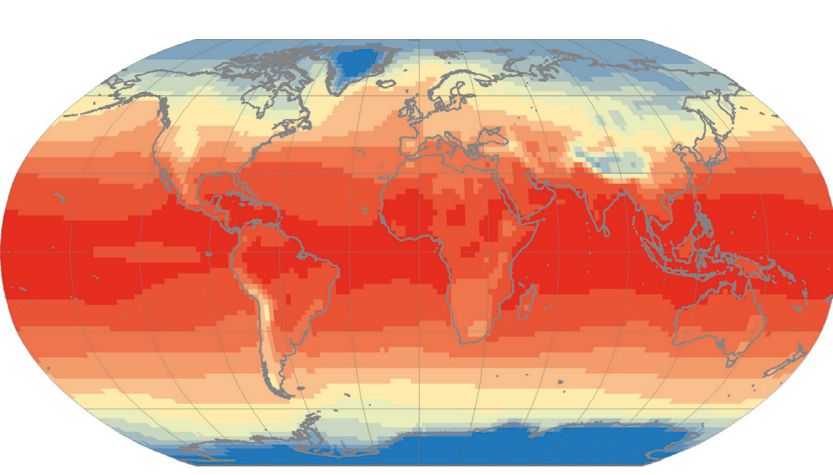

(a)

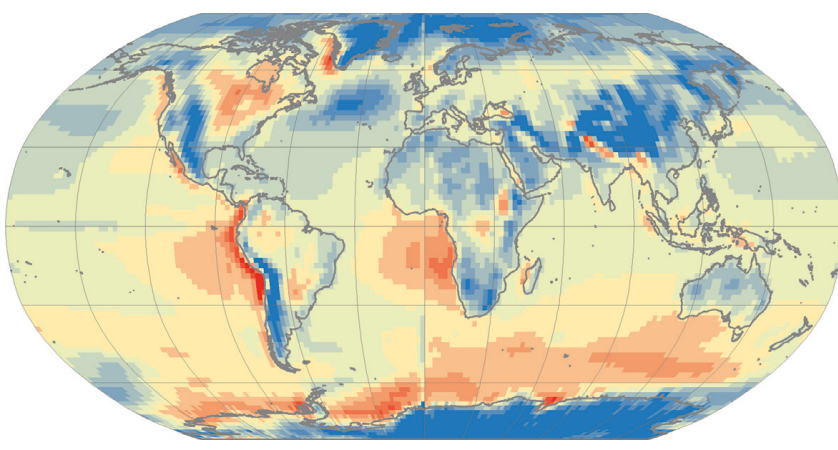

(b)

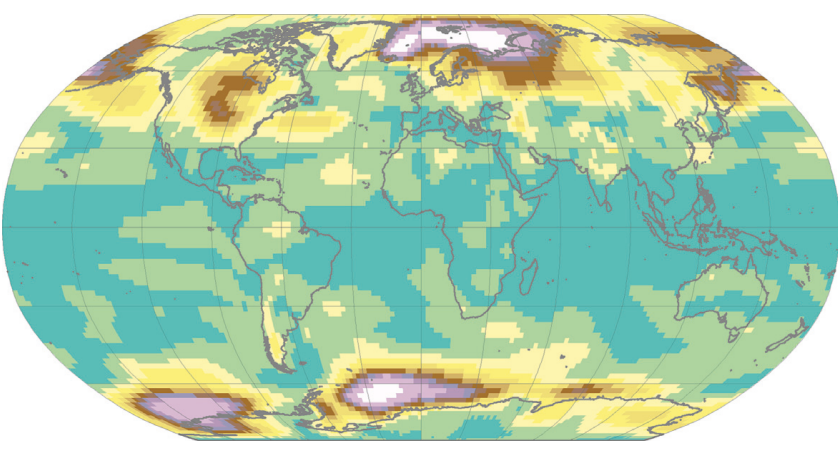

(c)

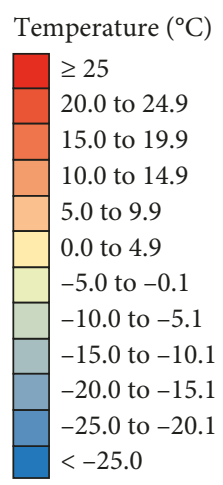

Temperature bias $\left({ }^{\circ} \mathrm{C}\right)$
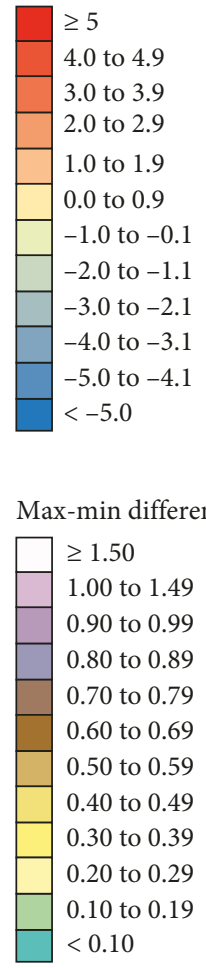

$<0.10$

Figure 2: (a) Average annual $2 \mathrm{~m}$ temperature in the CNRM-CM5.1 ensemble mean, (b) its bias against the NOAA-CIRES 20th Century Reanalysis, version $2 c$, and (c) differences between "warmest" and "coldest" ensemble members in individual grid points. All maps represent the 1956-2005 period.

well; however, some notable biases were found. Over land, negative SLP bias was located in midlatitudes of the Northern Hemisphere (analysed in more detail in Section 4) and in the Antarctic (Figure 3(b)). The most distinctive negative SLP biases over oceans were found in the eastern Pacific Ocean and the southeastern Atlantic Ocean, and the biases were related to overestimated temperature in these regions. By contrast, positive SLP bias was found over western parts of the United States, Mexico, the Tibetan Plateau, the Arctic Ocean, and the Southern Ocean. Differences between ensemble members with highest/lowest SLP (in individual grid points; Figure 3(c)) are analogous to those obtained from temperature output (Figure 2(c)). The best agreement between individual ensemble members was found in the Tropics (especially over the Indian Ocean), while the largest differences were over polar regions and in Azores and North Pacific anticyclones.

Focusing on individual seasons, the smallest global temperature bias was found during the boreal summer $\left(-2.4^{\circ} \mathrm{C}\right.$ in the $1980-2005$ period; Table 2$)$. In the remaining seasons, the biases were somewhat larger (roughly $-2.9^{\circ} \mathrm{C}$ ) and quite similar. Analogously to the annual bias, seasonal biases were stable during different time periods and comparable among individual ensemble members.

The global pattern of temperature bias varied across individual seasons (Figure 4). The substantial negative bias in Greenland and Arctic, which was especially pronounced in boreal spring and winter (Figures 4(a) and 4(d)), almost 

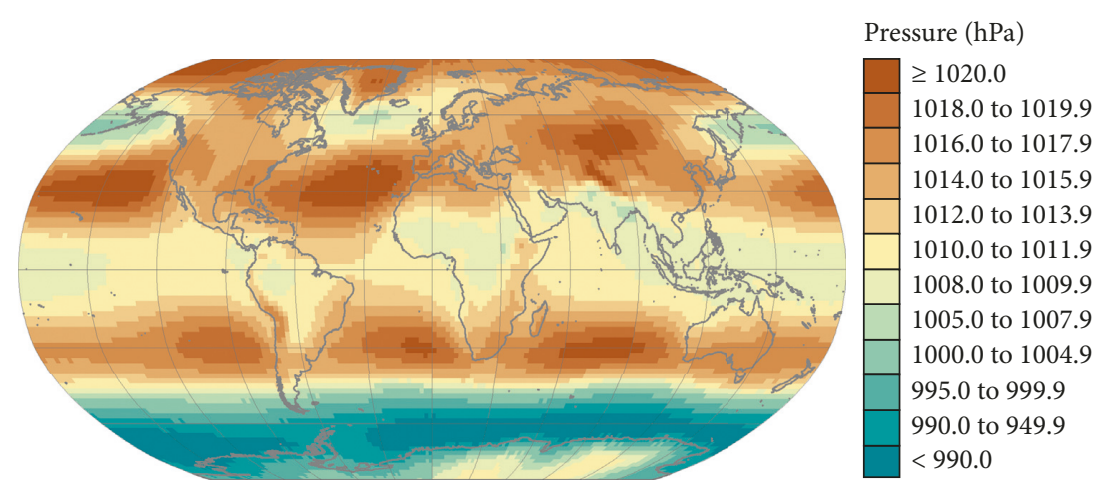

(a)
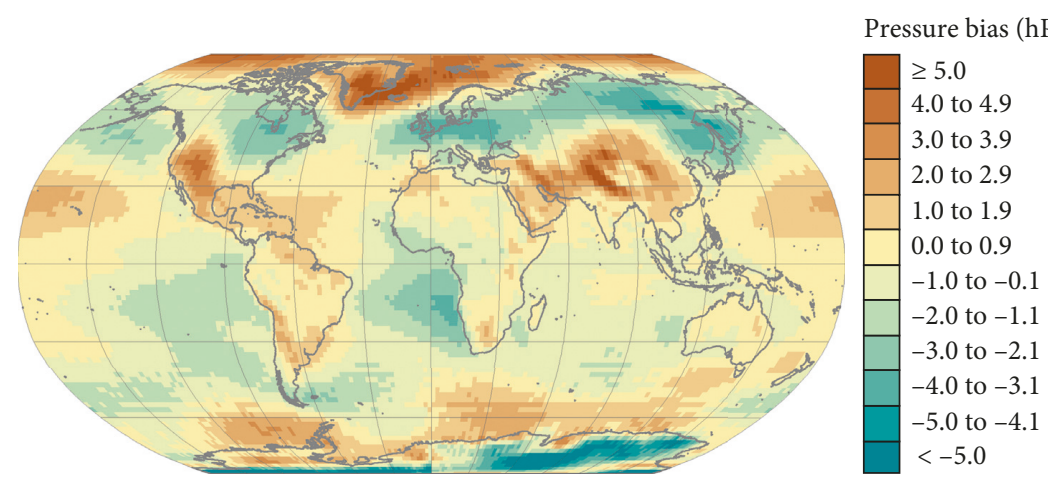

(b)

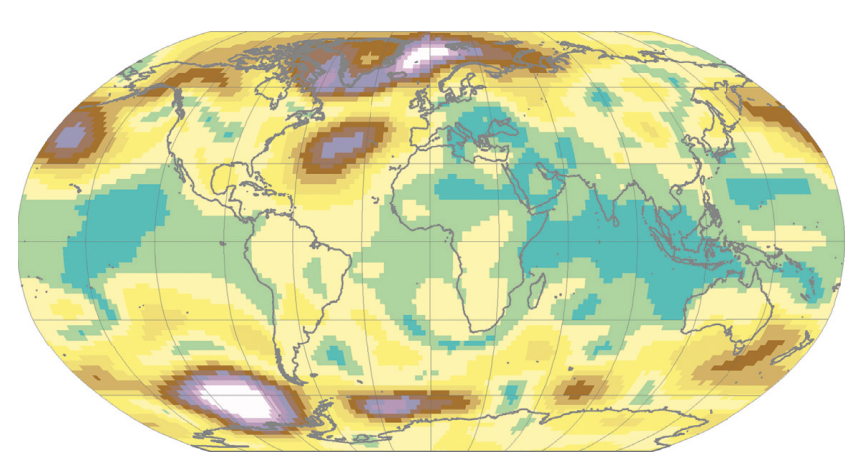

Max-min difference (hPa)

(c)

FIgure 3: (a) Average annual sea-level pressure in the CNRM-CM5.1 ensemble mean, (b) its bias against the NOAA-CIRES 20th Century Reanalysis, version $2 c$, and (c) differences between ensemble members with the highest/lowest sea-level pressure value in individual grid points. All maps represent the 1956-2005 period.

TABle 2: Seasonal temperature biases $\left({ }^{\circ} \mathrm{C}\right)$ in the CNRM-CM5.1 ensemble mean during four time periods.

\begin{tabular}{lcccc}
\hline Period & MAM $\left({ }^{\circ} \mathrm{C}\right)$ & JJA $\left({ }^{\circ} \mathrm{C}\right)$ & SON $\left({ }^{\circ} \mathrm{C}\right)$ & DJF $\left({ }^{\circ} \mathrm{C}\right)$ \\
\hline $1980-2005$ & -2.9 & -2.4 & -2.8 & -2.8 \\
$1956-2005$ & -2.9 & -2.6 & -2.9 & -2.9 \\
$1906-2005$ & -2.9 & -2.5 & -2.9 & -2.9 \\
$1851-2005$ & -2.9 & -2.6 & -3.0 & -2.9 \\
\hline
\end{tabular}

MAM: March 1-May 31; JJA: June 1-July 31; SON: September 1-November 30; DJF: December 1-February 28.

disappeared during boreal summer (Figure 4(b)). Analogously to the Arctic, the strong negative bias over the Antarctic was reduced in austral summer (Figure 4(d)). The aforementioned positive bias over eastern North America was most pronounced during the boreal autumn, when its values exceeded $5^{\circ} \mathrm{C}$ in some grid points. The oceanic temperature bias dipole was least distinctive during boreal autumn. On the contrary, the eastern Pacific Ocean and the southeastern Atlantic Ocean regions with warm biases were relatively stable during all seasons.

No considerable differences in the magnitude of the SLP bias were found among individual seasons, except for the Antarctic Ocean and the Southern Ocean (Figure 5). The underestimated SLP in Northern midlatitudes and over the upwelling regions in the eastern Pacific Ocean and the southeastern Atlantic Ocean was also fairly stable during the year. The positive SLP bias over the western parts of the United States, Mexico, and the Tibetan Plateau was 


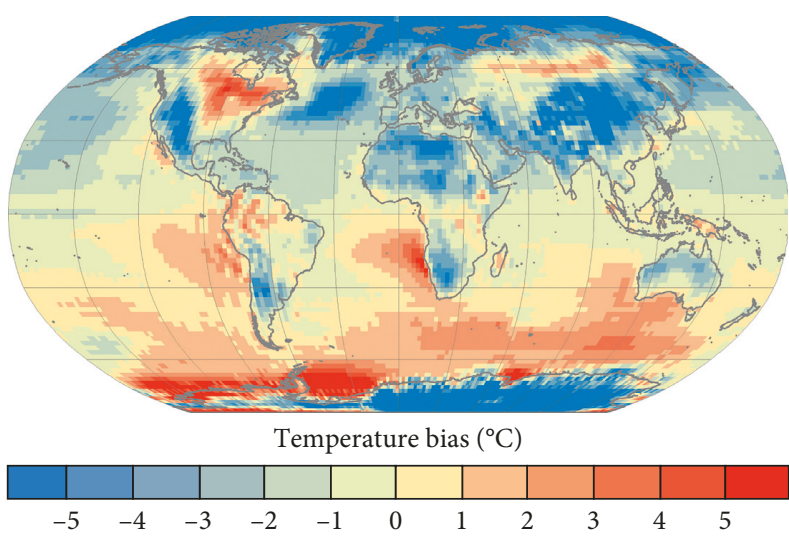

(a)

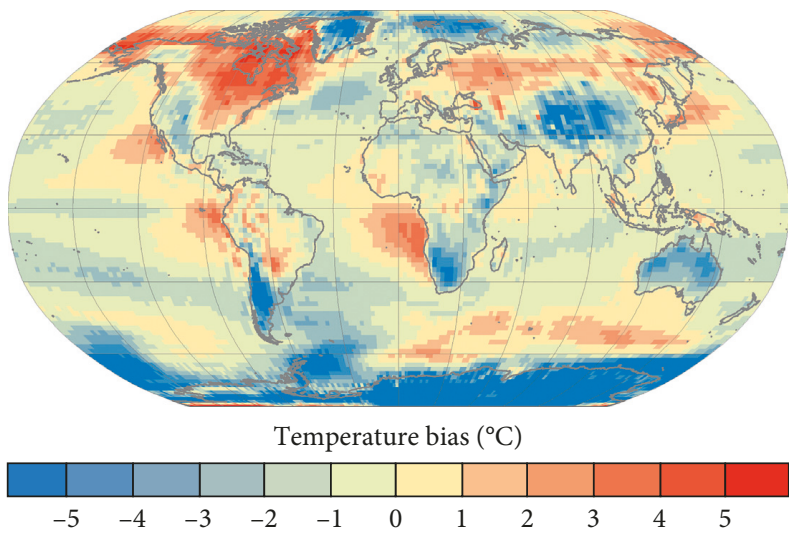

(c)

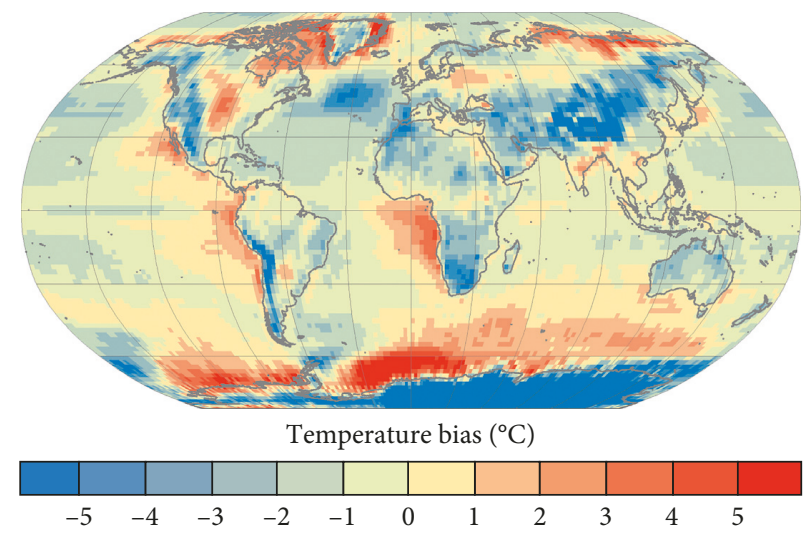

(b)

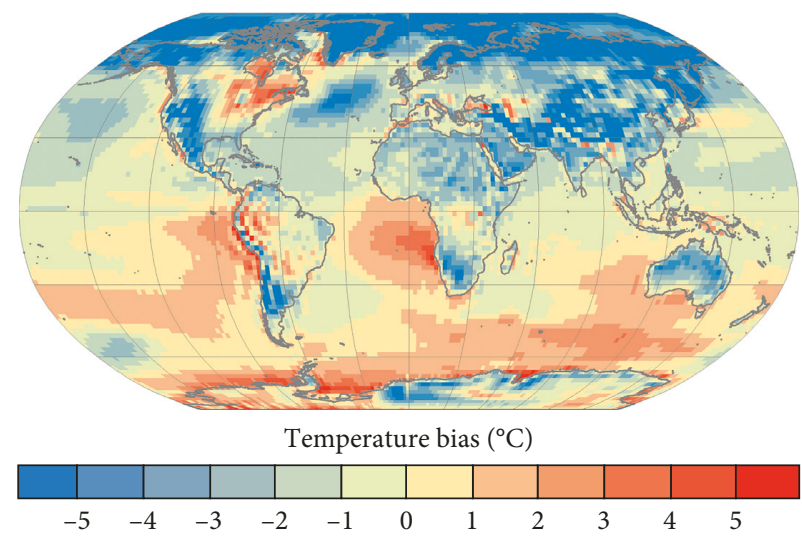

(d)

Figure 4: Average seasonal $2 \mathrm{~m}$ temperature bias in the CNRM-CM5.1 ensemble mean for the 1956-2005 period: (a) boreal spring (March-May), (b) boreal summer (June-August), (c) boreal autumn (September-November), and (d) boreal winter (December-February).

a year-round feature; however, it was least distinctive during the boreal summer.

\section{Northern Hemispheric Wintertime Circulation Types over Midlatitudes}

In this section, we evaluated the capability of CNRM-CM5.1 to simulate seasonal frequencies of flow types over three midlatitude regions (North America, Europe, and East Asia). Over North America during winter and spring, the most frequent northerly advection (occurring on about one-fifth of days) was underestimated in all three model integrations, in which the frequency of the northern circulation type varied between $15 \%$ and $17 \%$ (Figure 6(a)). The occurrence of the types with advection from northeast was also suppressed in the simulations. By contrast, advection from west and northwest and the frequency of the cyclonic type were overestimated, indicating a too frequent zonal flow in simulated data during these seasons. These synopticscale anomalies can be clearly linked to biases in the mean SLP gradient over North America, that is, to the positive SLP bias over western parts of the United States and Mexico and the negative bias over Alaska and Canada (Figures 5(a) and 5(d)). Furthermore, these errors in atmospheric dynamics can be linked to positive winter temperature biases
(Figure 4(d)), since the types that are associated with the advection of relatively cold Arctic air or the development of cold continental stagnant air occur with lower frequency in the model outputs. The underestimation of northerly types was found also during summer and autumn. By contrast, CNRM-CM5.1 simulated too frequent easterly, southeasterly, and southerly advection in these seasons (Figure 6(a)). The largest temperature anomaly during autumn was not clearly related to biases in large-scale flow, and this error would be possibly associated with land-atmosphere interactions.

Too frequent westerly advection was also found over Europe (except during the summer season; Figure 6(b)). Its observed frequency during winter $(20 \%)$ was considerably overestimated in CNRM-CM5.1, ranging from 25\% to $27 \%$. This overestimation is less pronounced in the transient seasons (spring and autumn), and the summertime frequency of the westerly flow type is underestimated in CNRM-CM5.1. The model also simulated too frequent south-westerly advection, while the frequency of easterly and south-easterly circulation types was underestimated (except in summer). Interestingly, these errors did not result in a notable wintertime positive temperature bias over Europe, probably due to underestimated temperature in the North Atlantic Ocean in the model simulations. 


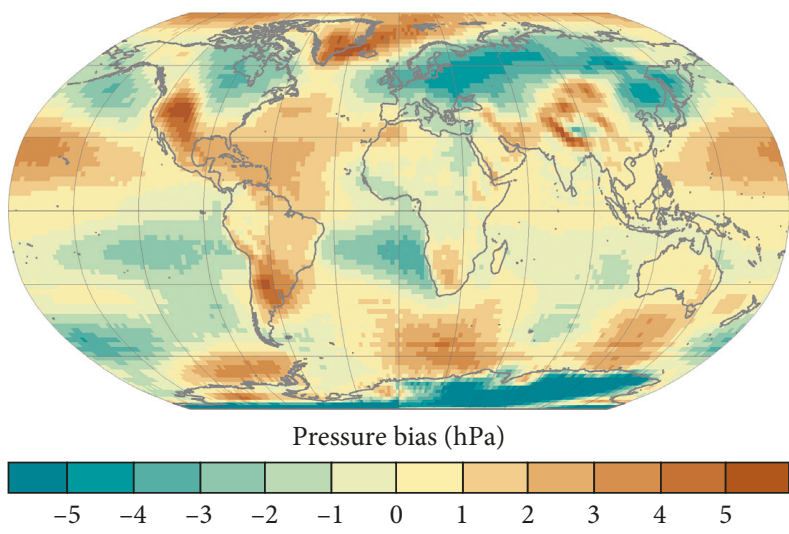

(a)

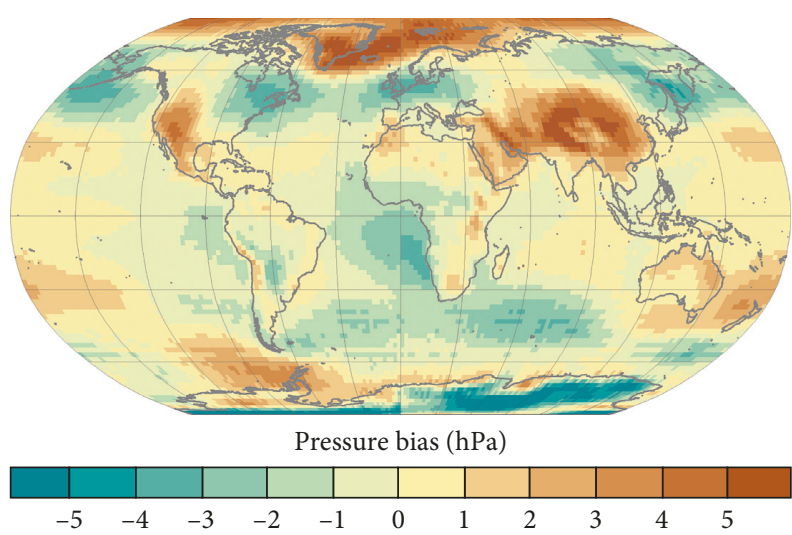

(c)

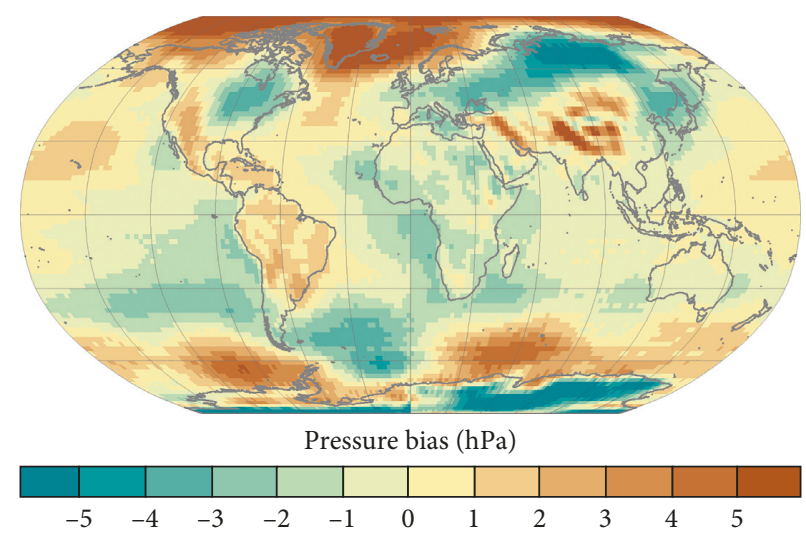

(b)

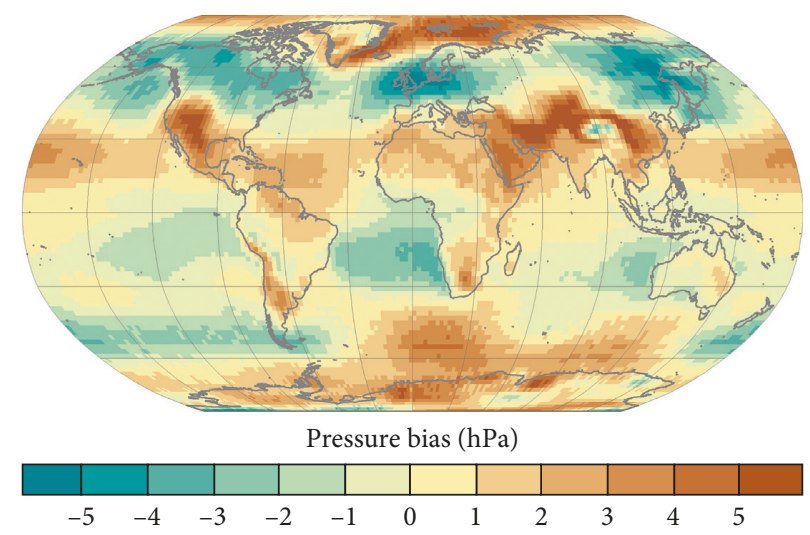

(d)

Figure 5: Average seasonal sea-level pressure bias in the CNRM-CM5.1 ensemble mean for the 1956-2005 period: (a) boreal spring (March-May), (b) boreal summer (June-August), (c) boreal autumn (September-November), and (d) boreal winter (December-February).

Over East Asia, CNRM-CM5.1 simulated the prevailing wintertime monsoon-related northerly advection quite well (Figure 6(c)); however, the frequencies of the northwestern and western circulation types were markedly overestimated at the expense of the northeastern circulation type. The latter is linked to the bias in the zonal SLP gradient (Figure 5(d)). By contrast, CNRM-CM5.1 failed to simulate the prevailing southerly advection associated with monsoon during summer. The frequency of the southerly type was almost halved in CNRM-CM5.1 compared to the reanalysis.

In all, too frequent zonal flow was found across the Northern midlatitudes. This bias is clearly associated with overestimated/underestimated SLP in two belt-shaped patterns, one between about 20 and $30^{\circ} \mathrm{N}$ and the other around about $55^{\circ} \mathrm{N}$ (Figure 5(d)). Furthermore, the underestimated SLP in midlatitudes is linked to the overestimated (underestimated) frequency of strongly cyclonic (anticyclonic) circulation types in all examined regions (Figure 6).

\section{Discussion}

CNRM-CM5.1 exhibited similar temperature biases as have been shown for the CMIP5 multimodel mean, with respect to their spatial patterns and magnitude [25]. Pronounced warm biases were found over upwelling regions in the southeastern Atlantic Ocean and Pacific Ocean. This bias was already reported for the CMIP3 GCMs, and it was linked to erroneous southward displacement of the intertropical convergence zone, subsequent modification of westerly winds, and deepened thermocline, which reduce upwelling of cold water. In addition, the bias is related also to improper simulation of low-altitude clouds in these regions [26]. An analogous issue was reported for CMIP5 simulations [27], and Wang et al. [3] revealed other interhemispheric links between these warm biases and distant large-scale factors, such as weaker monsoons in the Northern Hemisphere. Therefore, a reduction of these biases cannot be based on correction of regional processes only but has to be carried out with a complex insight.

Another notable deficiency of CMIP5 GCMs (including CNRM-CM5.1) is the oceanic bias dipole, probably originating from a weakened northward heat transport due to a reduced AMOC [3], resulting in the warmer Southern Ocean and the colder North Atlantic Ocean compared to the reference data. The cold bias over the North Atlantic may possibly be related to the persisting negative phase of Atlantic multidecadal oscillation [28] in the model outputs. CMIP3 GCMs, however, have difficulties to simulate this feature, mainly due to a low signal-to-noise ratio and a long period of oscillation [29], and it is possible that 

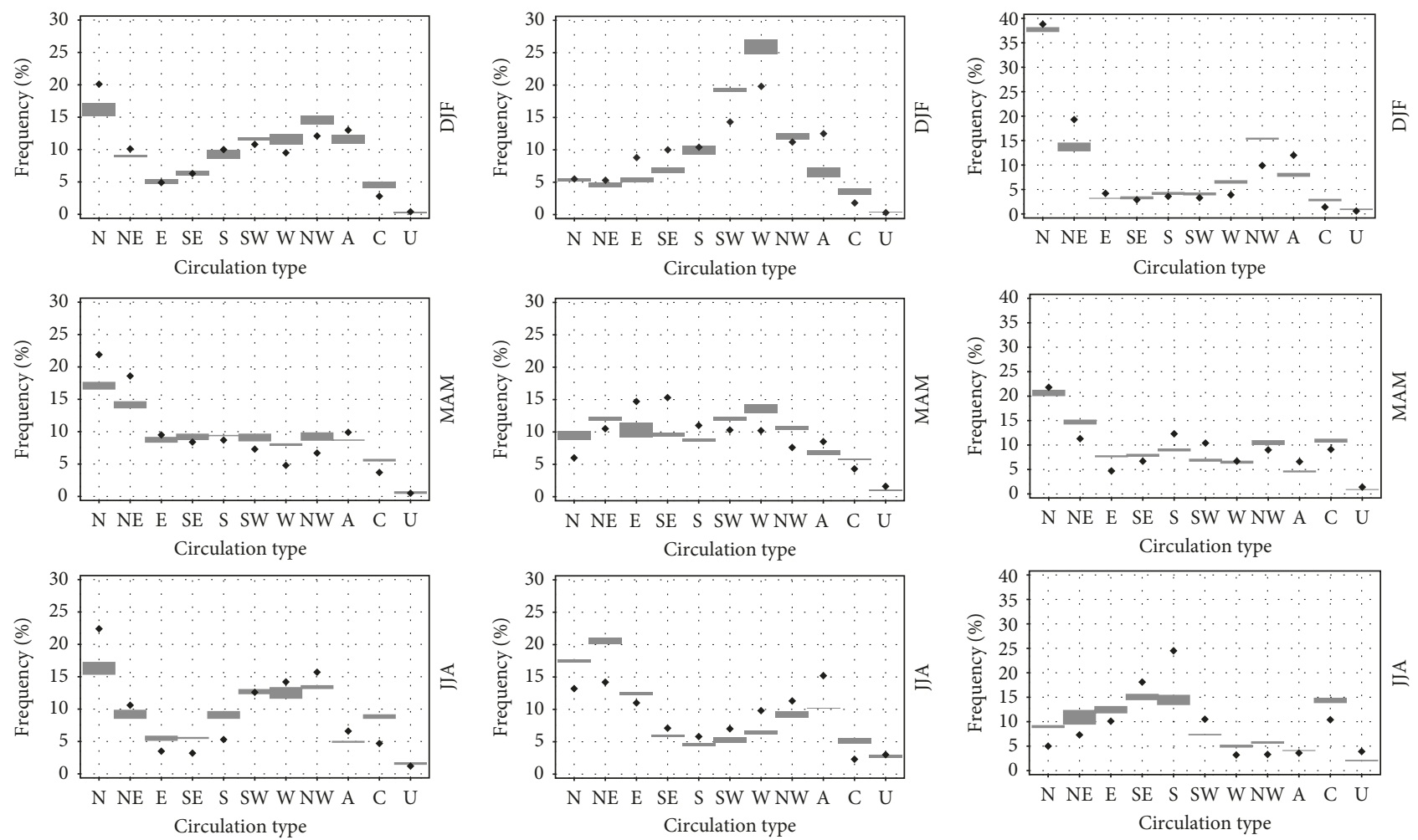

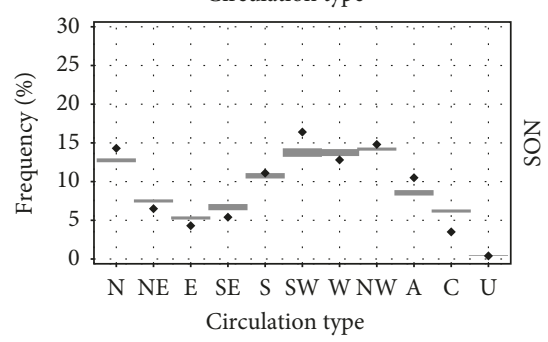

(a)

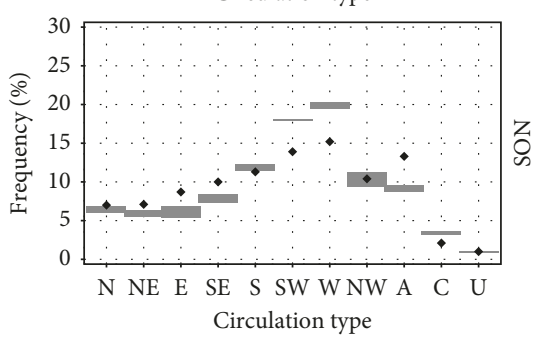

(b)

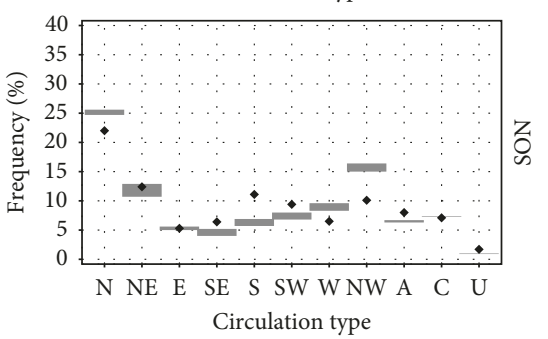

(c)

FIgURE 6: Mean wintertime frequency of circulation types in NOAA-CIRES 20th Century Reanalysis (black dots) over (a) North America, (b) Europe, and (c) East Asia. Grey bands indicate a span between individual ensemble members in CNRM-CM5.1 for each circulation type.

CNRM-CM5.1 suffers from the same deficiency as well. The negative temperature bias in northern Atlantic and Europe may also possibly be linked to improper simulation of Gulf Stream, which carries warm water erroneously towards the Canadian Archipelago with consequent impacts on the simulated North American climate. Huszar et al. [21] reported an overestimated sea ice extent in the CNRM-CM5.1, which may explain the strong cold bias over the Arctic Ocean in spring and winter found in our study.

Besides polar regions, considerable negative temperature biases over land were found over mountainous areas, which is in accordance with IPCC [25] and Su et al. [30] who evaluated the performance of CMIP5 GCMs over the Tibetan Plateau and suggested that the negative bias may be linked to snow-cover feedback processes in the models. Besides these physical processes, however, the bias may be affected by a simple representation of orography or a lack of observed data in these remote areas that affects the performance of the reanalysis. In addition, it should be noted that the magnitude of biases may be influenced by a selection of reference data (i.e., the NOAA-CIRES 20th Century Reanalysis V2c), inasmuch as Stryhal and Huth [31] showed that the choice of different reanalyses can have a profound effect on GCM validation over Europe in winter.

Temperature differences between individual ensemble members are relatively small on the global scale, which is in accordance with Kharin et al. [32], who showed that a spread between individual GCMs was larger compared to the difference between ensemble members of one particular GCM. In our study, the difference between the ensemble members in simulating temperature was smallest over equatorial areas and gradually increased poleward. The largest discrepancies were found over polar oceans, in accordance with Kharin et al. [32], and may be related to different boundaries of sea ice extent in individual ensemble members that would considerably alter a surface climate.

Small differences among the individual ensemble members were found also when assessing differences in sea-level pressure fields (except polar regions) and frequencies of circulation types over North America, Europe, 
and East Asia. The common deficiency in these three regions was an overestimated frequency of zonal flow, which is probably associated with the known issue of GCMs not being able to correctly simulate the occurrence of atmospheric blocking $[33,34]$.

\section{Conclusions}

We evaluated temperature and SLP biases and frequency of circulation types in three historical ensemble members of CNRM-CM5.1 GCM against the NOAA-CIRES 20th Century Reanalysis. The main conclusions are summarised as follows:

(i) The CNRM-CM5.1 model had a relatively good skill in reproducing global temperature patterns; however, it exhibited drawbacks similar to those reported for other CMIP5 GCMs. An oceanic bias dipole pattern is present in CNRM-CM5.1, resulting in a too warm Southern Ocean and an excessively cold North Atlantic Ocean and Arctic Ocean.

(ii) Another deficiency shared with the majority of CMIP5 models is a positive temperature bias in upwelling regions along western coasts of Africa and Southern America (locally exceeding $5^{\circ} \mathrm{C}$ ). This temperature bias was associated with too low sealevel pressure in these regions.

(iii) The most apparent biases were present in all three ensemble members, regardless of the member's initial conditions, and, therefore, are rather a result of model errors than simulated natural variability. This holds not only for mean seasonal and annual temperature and SLP patterns but even for the considerably more chaotic and variable synopticscale circulation over three northern midlatitude regions.

(iv) CNRM-CM5.1 overestimated the frequency of zonal flow over North America, Europe, and East Asia. The considerable positive wintertime temperature bias in North America was associated with suppressed northerly advection of cold air from the Arctic in CNRM-CM5.1 and was found in all ensemble members.

\section{Data Availability}

The outputs of the CNRM-CM5.1 global climate model can be obtained from the ESFG data node (https://esg-dn1.nsc. liu.se/projects/esgf-liu/). NOAA-CIRES 20th Century Reanalysis V2c is available through the ESRL website (https:// www.esrl.noaa.gov/psd/data/gridded/data.20thC_ReanV2c. html).

\section{Conflicts of Interest}

The authors declare that there are no conflicts of interest regarding the publication of this article.

\section{Acknowledgments}

This work was supported by the Ministry of Education, Youth and Sports of the Czech Republic within the National Sustainability Program I (NPU I), Grant no. LO1415. The authors acknowledge the CNRM-CM5.1 global climate model developed by CNRM-GAME (Centre National de Recherches Météorologiques-Groupe d'études de l'Atmosphère Météorologique) and Cerfacs (Centre Européen de Recherche et de Formation Avancée). The authors also acknowledge the Twentieth Century Reanalysis Project version $2 \mathrm{c}$ dataset that is provided by the U.S. Department of Energy, Office of Science Biological and Environmental Research (BER), and by the National Oceanic and Atmospheric Administration Climate Program Office. The authors thank Jan Stryhal, Institute of Atmospheric Physics, Prague, for his valuable comments on the draft of the paper.

\section{References}

[1] J. Sillmann, V. V. Kharin, X. Zhang, F. W. Zwiers, and D. Bronaugh, "Climate extremes indices in the CMIP5 multimodel ensemble: part 1. Model evaluation in the present climate," Journal of Geophysical Research: Atmospheres, vol. 118, no. 4, pp. 1716-1733, 2013.

[2] A. Voldoire, E. Sanchez-Gomez, D. Salaz y Mélia et al., "The CNRM-CM5.1 global climate model: description and basic evaluation," Climate Dynamics, vol. 40, no. 9-10, pp. 20912121, 2013.

[3] C. Wang, L. Zhang, and S. Lee, "A global perspective on CMIP5 climate model biases," Nature Climate Change, vol. 4, no. 3, pp. 201-205, 2014.

[4] K. E. Taylor, R. J. Stouffer, and G. A. Meehl, "An overview of CMIP5 and the experiment design," Bulletin of the American Meteorological Society, vol. 93, no. 4, pp. 485-498, 2012.

[5] S. Majahan, "Impact of the Atlantic meridional overturning circulation (AMOC) on Arctic surface air temperature and sea ice variability," Journal of Climate, vol. 24, no. 24, pp. 6573-6581, 2011.

[6] J. C. Stroeve, V. Kattsov, A. Barrett et al., "Trends in Arctic sea ice extent from CMIP5, CMIP3 and observations," Geophysical Research Letters, vol. 39, no. 16, pp. 1-7, 2012.

[7] J. Turner, T. J. Bracegirdle, T. Phillips et al., "An initial assessment of Antarctic sea ice extent in the CMIP5 models," Journal of Climate, vol. 26, no. 5, pp. 1473-1484, 2013.

[8] R. Jaiser, K. Dethloff, D. Handorf et al., "Impact of sea ice cover changes on the Northern Hemisphere atmospheric winter circulation," Tellus A: Dynamic Meteorology and Oceanography, vol. 64, no. 1, p. 11595, 2012.

[9] J. Screen, I. Simmons, C. Deser, and R. Tomas, “The atmospheric response to three decades of observed Arctic sea ice loss," Journal of Climate, vol. 26, no. 4, pp. 1230-1248, 2012.

[10] J. A. Francis, S. J. Vavrus, and J. Cohen, "Amplified Arctic warming and mid-latitude weather: new perspectives on emerging connections," Wiley Interdisciplinary Reviews: Climate Change, vol. 8, no. 5, p. e474, 2017.

[11] S. Yang and J. H. Christensen, "Arctic sea ice reduction and European cold winters in CMIP5 climate change experiments," Geophysical Research Letters, vol. 39, no. 20, article L20707, 2012.

[12] Q. Tang, X. Zhang, X. Yang, and J. A. Francis, "Cold winter extremes in northern continents linked to Arctic sea ice loss," 
Environmental Research Letters, vol. 8, no. 1, article 014036, 2013.

[13] R. T. Sutton and B. Dong, "Atlantic Ocean influence on a shift in European climate in the 1990s," Nature Geoscience, vol. 5, no. 11, pp. 788-792, 2012.

[14] Y. Zhou and Z. Wu, "Possible impacts of mega-El Niño/ Southern Oscillation and Atlantic multidecadal oscillation on Eurasian heatwave frequency variability," Quarterly Journal of the Royal Meteorological Society, vol. 142, no. 697, pp. 1647$1661,2016$.

[15] J. Ma and S. P. Xie, "Regional patterns of sea surface temperature change: a source of uncertainty in future projections of precipitation and atmospheric circulation," Journal of Climate, vol. 26, no. 8, pp. 2482-2501, 2013.

[16] T. G. Shepherd, "Atmospheric circulation as a source of uncertainty in climate change projections," Nature Geoscience, vol. 7, no. 10, pp. 703-708, 2014.

[17] E. Hawkins and R. Sutton, "The potential to narrow uncertainty in regional climate predictions," Bulletin of the American Meteorological Society, vol. 90, no. 8, pp. 1095-1107, 2009.

[18] R. H. Moss, J. A. Edmonds, K. A. Hibbard et al., "The next generation of scenarios for climate change research and assessment," Nature, vol. 463, no. 7282, pp. 747-756, 2010.

[19] C. Deser, A. Phillips, V. Bourdette, and H. Teng, "Uncertainty in climate change projections: the role of internal variability," Climate Dynamics, vol. 38, no. 3-4, pp. 527-546, 2012.

[20] J. W. Hurrell and C. Deser, "North Atlantic climate variability: the role of the North Atlantic Oscillation," Journal of Marine Systems, vol. 79, no. 3-4, pp. 231-244, 2010.

[21] P. Huszar, H. Teyssèdre, M. Michou et al., "Modeling the present and future impact of aviation on climate: an AOGCM approach with online coupled chemistry," Atmospheric Chemistry and Physics, vol. 13, no. 19, pp. 10027-10048, 2013.

[22] G. P. Compo, J. S. Whitaker, P. D. Sardeshmukh et al., "The twentieth century reanalysis project," Quarterly Journal of the Royal Meteorological Society, vol. 137, no. 654, pp. 1-28, 2011.

[23] A. F. Jenkinson and F. P. Collison, An Initial Climatology of Gales over the North Sea, Synoptic Climatology Branch Memorandum No. 62, Meteorological Office, Bracknell, UK, 1977.

[24] S. Blenkinsop, P. D. Jones, S. R. Dorling, and T. J. Osborn, "Observed and modelled influence of atmospheric circulation on central England temperature extremes," International Journal of Climatology, vol. 29, no. 11, pp. 1642-1660, 2009.

[25] International Panel on Climate Change (IPCC), Climate Change 2013: The Physical Science Basis, Cambridge University Press, Cambridge, UK, 2013.

[26] I. Richter and S.-P. Xie, "On the origin of equatorial Atlantic biases in coupled general circulation models," Climate Dynamics, vol. 31, no. 5, pp. 587-598, 2008.

[27] I. Richter, S.-P. Xie, S. K. Behera et al., "Equatorial Atlantic variability and its relation to mean state biases in CMIP5," Climate Dynamics, vol. 42, no. 1-2, pp. 171-188, 2014.

[28] Y. Peings, G. Simpkins, and G. Magnusdottir, "Multidecadal fluctuations of the North Atlantic Ocean and feedback on the winter climate in CMIP5 control simulations," Journal of Geophysical Research: Atmospheres, vol. 121, no. 6, pp. 25712592, 2016.

[29] A. Stoner, K. Hayhoe, and D. Wuebbles, "Assessing general circulation model simulations of atmospheric teleconnection patterns," Journal of Climate, vol. 22, no. 16, pp. 4348-4372, 2009.
[30] F. Su, X. Duan, D. Chen et al., "Evaluation of the global climate models in the CMIP5 over the Tibetan Plateau," Journal of Climate, vol. 26, no. 10, pp. 3187-3208, 2013.

[31] J. Stryhal and R. Huth, "Classifications of winter EuroAtlantic circulation patterns: an intercomparison of five atmospheric reanalyses," Journal of Climate, vol. 30, no. 19, pp. 7847-7861, 2017.

[32] V. V. Kharin, F. W. Zwiers, X. Zhang, and G. C. Hegerl, "Changes in temperature and precipitation extremes in the IPCC ensemble of global coupled model simulations," Journal of Climate, vol. 20, no. 8, pp. 1419-1444, 2007.

[33] A. A. Scaife, T. Woollings, J. Knight et al., "Atmospheric blocking and mean biases in climate models," Journal of Climate, vol. 23, no. 23, pp. 6143-6152, 2010.

[34] M. Rohrer, M. Croci-Maspoli, and C. Appenzeller, "Climate change and circulation types in the Alpine region," Meteorologische Zeitschrift, vol. 26, no. 1, pp. 83-92, 2017. 

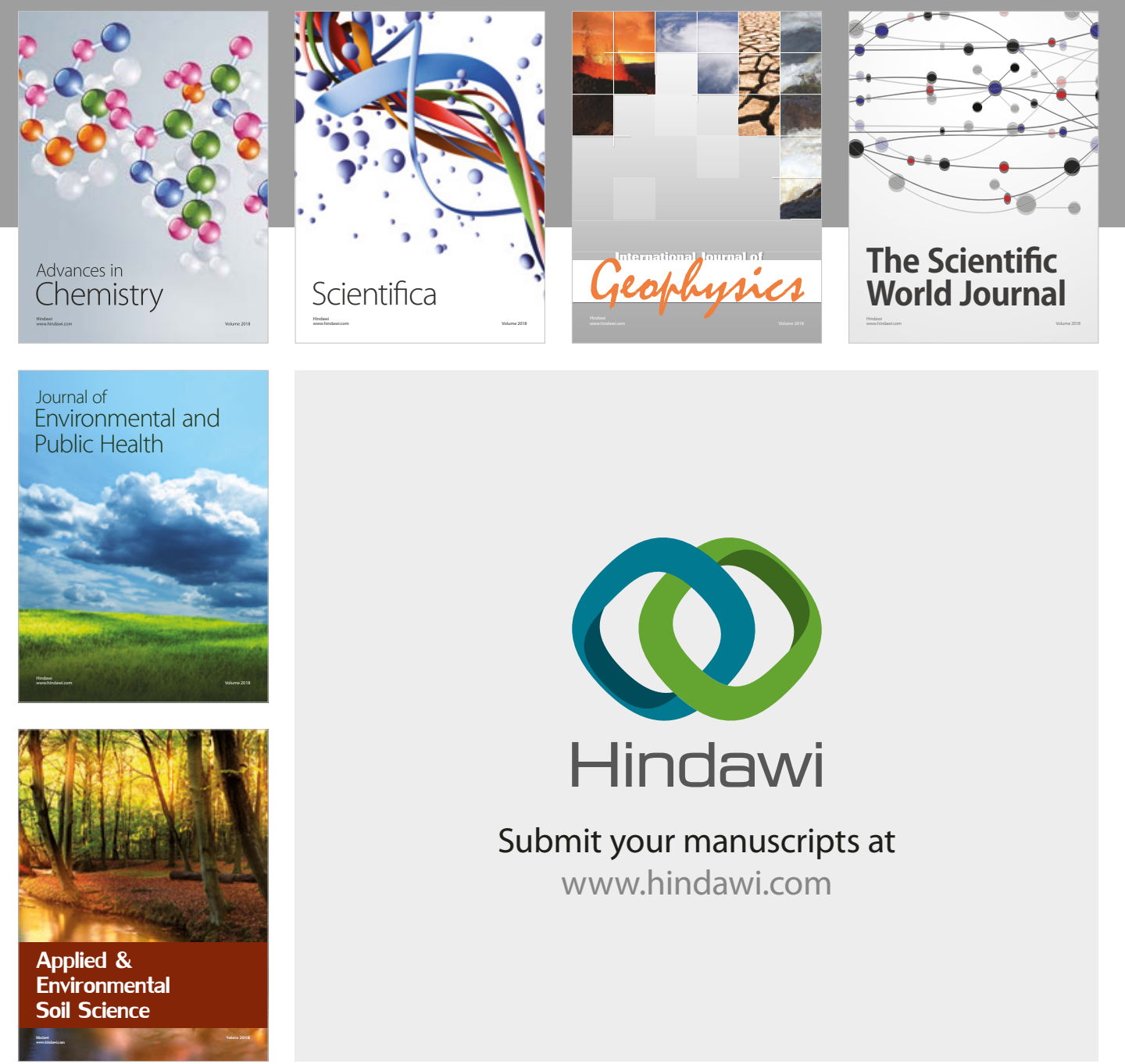

The Scientific

\section{World Journal}
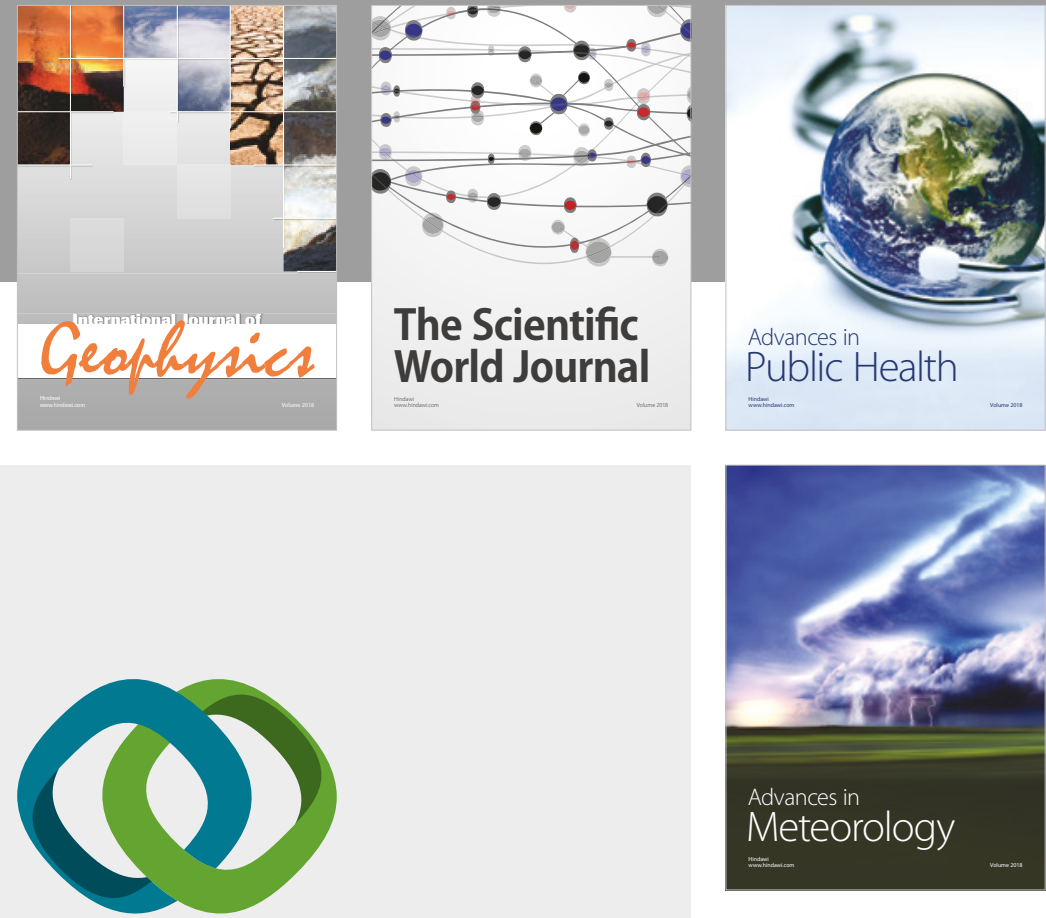

Advan

Public Health

\section{Hindawi}

Submit your manuscripts at

www.hindawi.com
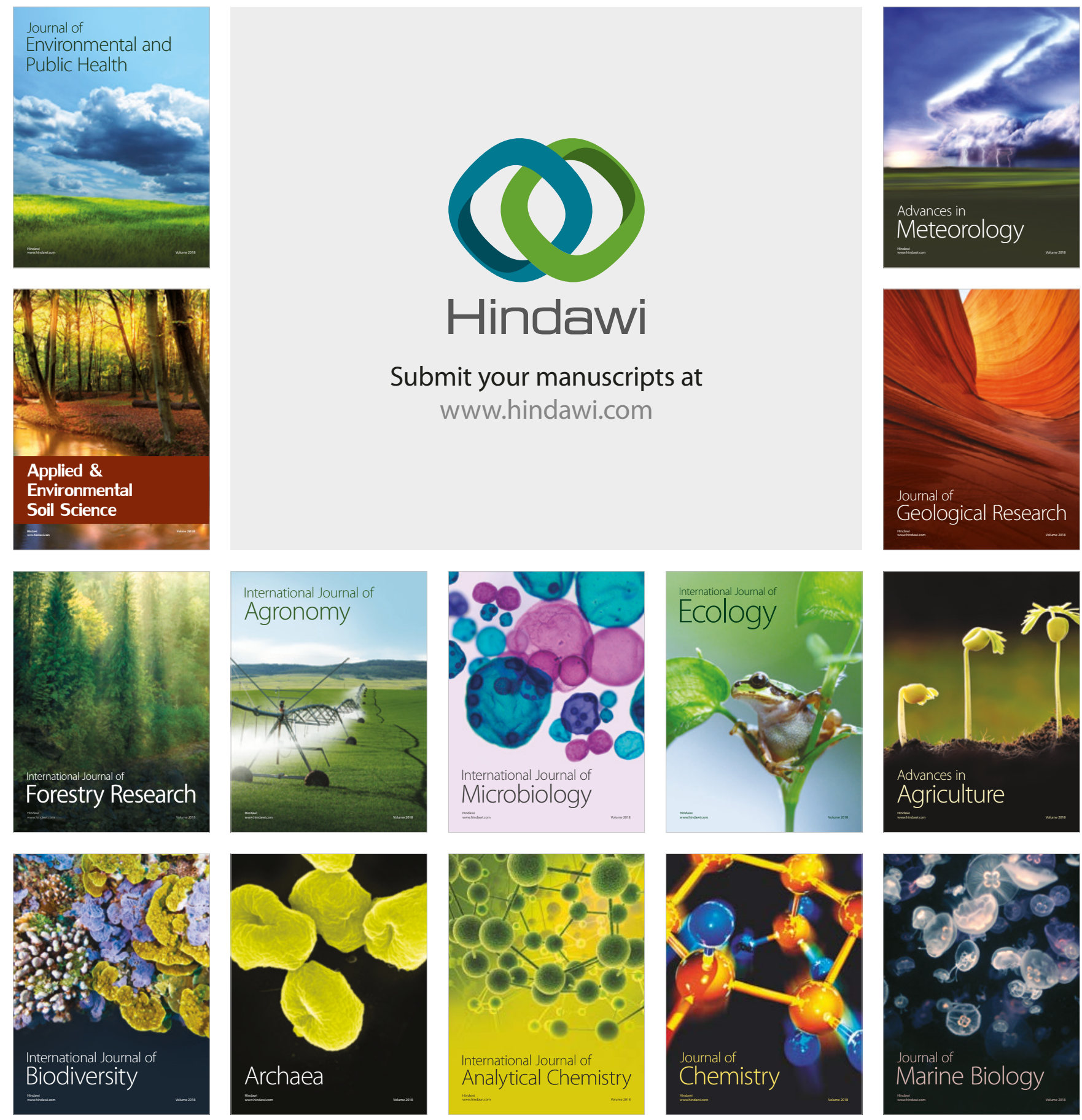